\title{
In Vitro Activities of Nisin and Nisin Derivatives Alone and In Combination with Antibiotics against Staphylococcus Biofilms
}

OPEN ACCESS

Edited by:

Marcelo Tolmasky,

California State University, Fullerton,

USA

Reviewed by:

Atte Von Wright,

University of Eastern Finland, Finland Alfonso Jc Soler-Bistue,

Institut Pasteur, France

Taoufik Ghrairi,

University Tunis-EIManar, Tunisia

*Correspondence:

Des Field

des.field@ucc.ie;

Colin Hill

c.hill@ucc.ie

Specialty section:

This article was submitted to Antimicrobials, Resistance and

Chemotherapy,

a section of the journa

Frontiers in Microbiology

Received: 08 February 2016

Accepted: 29 March 2016

Published: 18 April 2016

Citation:

Field D, O' Connor R, Cotter $P D$,

Ross RP and Hill C (2016) In Vitro Activities of Nisin and Nisin Derivatives Alone and In Combination with

Antibiotics against Staphylococcus Biofilms. Front. Microbiol. 7:508. doi: 10.3389/fmicb.2016.00508

\section{Des Field ${ }^{1 *}$, Rory O' Connor ${ }^{1}$, Paul D. Cotter ${ }^{2,3}$, R. Paul Ross ${ }^{4}$ and Colin Hill ${ }^{1,3 *}$}

${ }^{1}$ School of Microbiology, University College Cork, Cork, Ireland, ${ }^{2}$ Teagasc Food Research Centre, Cork, Ireland, ${ }^{3}$ APC Microbiome Institute, University College Cork, Cork, Ireland, ${ }^{4}$ College of Science, Engineering and Food Science, University College Cork, Cork, Ireland

The development and spread of pathogenic bacteria that are resistant to the existing catalog of antibiotics is a major public health threat. Biofilms are complex, sessile communities of bacteria embedded in an organic polymer matrix which serve to further enhance antimicrobial resistance. Consequently, novel compounds and innovative methods are urgently required to arrest the proliferation of drug-resistant infections in both nosocomial and community environments. Accordingly, it has been suggested that antimicrobial peptides could be used as novel natural inhibitors that can be used in formulations with synergistically acting antibiotics. Nisin is a member of the lantibiotic family of antimicrobial peptides that exhibit potent antibacterial activity against many Gram-positive bacteria. Recently we have used bioengineering strategies to enhance the activity of nisin against several high profile targets, including multi-drug resistant clinical pathogens such as methicillin-resistant Staphylococcus aureus, vancomycinresistant enterococci, staphylococci, and streptococci associated with bovine mastitis. We have also identified nisin derivatives with an enhanced ability to impair biofilm formation and to reduce the density of established biofilms of methicillin resistant S. pseudintermedius. The present study was aimed at evaluating the potential of nisin and nisin derivatives to increase the efficacy of conventional antibiotics and to assess the possibility of killing and/or eradicating biofilm-associated cells of a variety of staphylococcal targets. Growth curve-based comparisons established that combinations of derivatives nisin $\mathrm{V}+$ penicillin or nisin $14 \mathrm{~V}+$ chloramphenicol had an enhanced inhibitory effect against $S$. aureus SA113 and S. pseudintermedius DSM21284, respectively, compared to the equivalent nisin A + antibiotic combinations or when each antimicrobial was administered alone. Furthermore, the metabolic activity of established biofilms treated with nisin $\mathrm{V}+$ chloramphenicol and nisin $14 \mathrm{~V}+$ chloramphenicol combinations revealed a significant decrease in S. aureus SA113 and S. pseudintermedius DSM21284 biofilm viability, respectively, compared to the nisin A + antibiotic combinations as determined by the rapid colorimetric XTT assay. The results indicate that the activities of the nisin derivative and antibiotic combinations represent a significant improvement over that of the wild-type nisin and antibiotic combination and merit further investigation with a view to their use as anti-biofilm agents.

Keywords: biofilm, bacterial resistance, antimicrobial peptide, nisin, lantibiotic, bacteriocin, staphylococci, antibiotics 


\section{INTRODUCTION}

Staphylococcus aureus and S. pseudintermedius are major human and/or animal pathogens. For humans, S. aureus is the leading cause of bacteremia and infective endocarditis as well as osteoarticular, skin and soft tissue, pleuropulmonary, and devicerelated infections (Tong et al., 2015). It is also one of the main aetiological agents of bovine mastitis, resulting in significant economic losses to dairy enterprises (Viguier et al., 2009). Worryingly, the horizontal transmission of methicillin resistance to $S$. aureus in hospital and community settings, and the growing prevalence of these strains, presents a significant clinical challenge to the management of serious infections worldwide (Stryjewski and Corey, 2014). S. pseudintermedius has emerged over the last decade as a critically important, opportunistic animal pathogen responsible for skin, soft tissue, and surgical site infections (Ruscher et al., 2009; Murayama et al., 2013) that also has implications for public health as transmission between humans and animals has been described (Paul et al., 2011). Critically, antibiotic resistance and the ability to form biofilms (complex, sessile communities of bacteria embedded in an organic polymer matrix (Flemming and Wingender, 2010) contribute to the success of $S$. aureus and $S$. pseudintermedius as pathogens in healthcare, community and veterinary settings. Indeed, biofilm formation is now recognized as an important virulence factor in several Staphylococcus sp. (Otto, 2008), providing the bacteria with remarkable resistance to diverse chemical, physical and biological antimicrobial agents and is one of the main causes of persistent infection (Archer et al., 2011). In addition to antibiotic resistance and biofilm formation, the acquisition of other resistance genes and resistance-facilitating mutations in some staphylococci renders these strains impervious to many currently utilized antimicrobial agents (Livermore, 2000; Chambers and Deleo, 2009). As only a handful of new antimicrobials have been developed in the last decade, the further evolution of resistance poses a serious threat to public health. Therefore, there is an urgent need to identify new antimicrobial agents that are not covered by existing mechanisms of resistance. The development of anti-biofilm therapeutics has generally focused on interfering with quorum sensing, inhibition of adhesion, enhancement of dispersion, or bacteriophage-based treatments (Mataraci and Dosler, 2012). Another potential strategy to reduce biofilm-associated resistance is through synergistic effects of antimicrobial agents in combination, which can enhance antibiofilm activities and help to prevent or delay the emergence of resistance. One such group of compounds with immense potential for therapeutic use is the lantibiotic class of bacteriocins (bacterially derived antimicrobial peptides) (Cotter et al., 2005b, 2013). Lantibiotics are ribosomally synthesized peptides that are defined by the presence of unusual amino acids including lanthionine and/or methyllanthionine (Breukink and de Kruijff, 1999; Chatterjee et al., 2005; Bierbaum and Sahl, 2009). The most meticulously researched lantibiotic is nisin. Produced by Lactococcus lactis, nisin exhibits antibacterial activity against a wide range of Gram-positive bacteria, including foodborne pathogens such as staphylococci, bacilli and clostridia. Nisin is used as a food preservative in over 50 countries and has been approved in the EU and by the US Food and Drug Administration (FDA; Delves-Broughton et al., 1996). In addition, both nisin $\mathrm{A}$ (and its natural variant nisin $\mathrm{Z}$ ) are effective against the Gram-positive pathogens responsible for bovine mastitis and have been incorporated into a number of products devoted to restricting or treating such infections (Sears et al., 1992; Wu et al., 2007). Notably, in addition to being effective against planktonic cells of multi-drug resistant staphylococci (Dosler and Gerceker, 2011; Okuda et al., 2013), nisin has also demonstrated efficacy against biofilms (Corbin et al., 2011; Dosler and Mataraci, 2013; Okuda et al., 2013). Moreover, there is also a steadily growing number of engineered nisin peptides that demonstrate enhanced functionalities (activity and/or stability) which make them more attractive from a clinical perspective (Cotter et al., 2013; Field et al., 2015a). Indeed, the bioengineering of nisin has generated variants that exhibit not only improved antimicrobial activity against strains of clinical relevance (methicillin resistant $S$. aureus (MRSA), vancomycinresistant enterococci (VRE), vancomycin-intermediate $S$. aureus (VISA), methicillin-resistant S. pseudintermedius (MRSP), and C. difficile) but has also brought about the widening of its antimicrobial spectrum (Field et al., 2008, 2012; Molloy et al., 2013).

It has frequently been suggested that the efficacy of individual lantibiotics could be further boosted through combination with other antimicrobials or membrane-active substances (Cavera et al., 2015a). Indeed, several studies have demonstrated synergistic relationships between conventional antibiotics and lantibiotics (Brumfitt et al., 2002; Cavera et al., 2015b). For example, nisin displayed synergistic activity with the antibiotics colistin and clarithromycin against Pseudomonas aeruginosa (Giacometti et al., 2000), with penicillin, streptomycin, chloramphenicol and rifampicin against Pseudomonas fluorescens (Naghmouchi et al., 2012) and with ramoplanin and other non- $\beta$-lactam antibiotics against many strains of MRSA and VRE (Brumfitt et al., 2002). Similarly, nisin-ceftriaxone and nisin-cefotaxime were found to be highly synergistic against clinical isolates of Salmonella enterica serovar Typhimurium as evident by checkerboard and time-kill assays (Rishi et al., 2014). Notably, penicillin, ciprofloxacin and chloramphenicol displayed greater potency against biofilms of E. faecalis when used in combination with nisin (Tong et al., 2014). We have previously described a novel nisin variant with improved specific activity compared to nisin A against strains of $S$. pseudintermedius that was also more effective in preventing biofilm formation, and in reducing the biofilm mass formed on microtiter plates (Field et al., $2015 b)$. With this in mind, this study set out to investigate the ability of nisin and two enhanced nisin derivatives (nisin I4V and nisin M21V) in conjunction with a selection of currently utilized antibiotics to control a range of Staphylococcus sp., including human and animal associated clinical isolates with the ultimate aim of identifying superior anti-biofilm combinations. 


\section{MATERIALS AND METHODS}

\section{Bacterial Strains and Growth Conditions}

Nisin and nisin derivative producing L. lactis strains (Table 1) were grown in M17 broth supplemented with $0.5 \%$ glucose (GM17) or GM17 agar at $30^{\circ} \mathrm{C}$. E. coli was grown in LuriaBertani broth with vigorous shaking or agar at $37^{\circ} \mathrm{C}$. A variety of pathogenic staphylococcal targets were selected, including two MRSA clinical isolates (ST528 and ST530), 3 strains associated with animal infections (S. pseudintermedius DK729, S. pseudintermedius DSM21284, S. intermedius DSM20373), 3 isolates associated with bovine mastitis ( $S$. aureus DPC5243, S. aureus DPC5347, S. aureus RF122) and a strain of S. aureus (SA113) used as a representative staphylococcal organism in model virulence studies (Kristian et al., 2003; Kneuper et al., 2014; Table 1). S. pseudintermedius DK729, S. pseudintermedius DSM21284 and S. intermedius DSM20373 have previously been shown to form biofilms as determined by crystal violet staining (Field et al., 2015b). S. aureus SA113 has also demonstrated ability to form strong biofilms (Cramton et al., 1999). Staphylococcus strains were grown in cation-adjusted Mueller Hinton (CA-MH) (Oxoid) for minimum inhibitory concentration assays or Tryptic Soy Broth (TSB) (Merck) supplemented with 1\% Glucose at $37^{\circ} \mathrm{C}$ for biofilm assays. Antibiotics were used where indicated at the following concentrations: Chloramphenicol at 10 and $20 \mu \mathrm{g}$ $\mathrm{ml}^{-1}$, respectively, for L. lactis and E. coli.

\section{Minimum Inhibitory Concentration Assays}

Minimum inhibitory concentration determinations were carried out in triplicate in 96 well microtitre plates as described previously (Field et al., 2010, 2012, 2015b). Briefly, target strains were grown overnight in the appropriate conditions and medium, subcultured into fresh broth and allowed to grow to an $\mathrm{OD}_{600}$ of $\sim 0.5$, diluted to a final concentration of $10^{5} \mathrm{cfu} \mathrm{ml}^{-1}$ in a volume of $0.2 \mathrm{ml}$. Chloramphenicol, penicillin $\mathrm{G}$, ampicillin, vancomycin, streptomycin, tetracycline, erythromycin, ceftazidime, and cefuroxime (Sigma) were resuspended in CA-MH media to a stock concentration of 128 or $256 \mu \mathrm{g} / \mathrm{ml}$. The antibiotics were adjusted to 16,32 , or $64 \mu \mathrm{g} / \mathrm{ml}$ starting concentration and twofold serial dilutions of each compound were made in 96 well plates for a total of 12 dilutions. The target strain was then added and after incubation for $16 \mathrm{~h}$ at $37^{\circ} \mathrm{C}$ and the MIC was read as the lowest peptide concentration causing inhibition of visible growth.

\section{Nisin and Nisin Variant Purification}

Nisin and nisin derivatives were purified according to previously described protocols (Field et al., 2010; Molloy et al., 2013). Briefly, 21 of Tryptone Yeast (TY) broth were incubated for $20 \mathrm{~h}$ with $1 \%$ inoculum of an overnight culture of producing strain (nisin A, nisin $\mathrm{V}$, or nisin $\mathrm{I} 4 \mathrm{~V}$ ). This culture was centrifuged for $20 \mathrm{~min}$ at $7000 \mathrm{rpm}$. The supernatant was decanted and passed through $60 \mathrm{~g}$ of pre-equilibrated Amberlite XAD16 beads (Sigma-Aldrich). The beads were washed with $500 \mathrm{ml} \mathrm{30 \%} \mathrm{ethanol} \mathrm{and} \mathrm{eluted}$

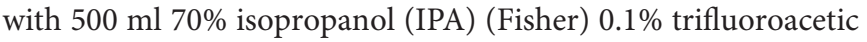
acid (TFA) (Sigma-Aldrich). Concomitantly, the cell pellets were resuspended in $300 \mathrm{ml}$ of $70 \%$ IPA $0.1 \%$ TFA and stirred at room temperature for 3 hours followed by centrifugation. This cell supernatant was combined with that referred to above and concentrated through rotary-evaporation (Buchi, Switzerland) to approximately $250 \mathrm{ml}$. Following $\mathrm{pH}$ adjustment to 4.0 further concentration was achieved through the use of a Phenomenex SPE C-18 column to a final volume of $60 \mathrm{ml} .8 \mathrm{ml}$ of this sample was concentrated, through rotary evaporation, to $2 \mathrm{ml}$ and purified through HPLC using a Phenomenex C12 Reverse-Phase (RP) HPLC column (Jupiter $4 \mu$ proteo $90 \AA$, $250 \mathrm{X} 10.0 \mathrm{~mm}, 4 \mu \mathrm{m})$. To facilitate this, a gradient of 30$50 \%$ acetonitrile (Fisher) containing $0.1 \%$ TFA was developed. The relevant fractions were collected and pooled, subjected

TABLE 1 | Bacterial strains utilized in this study.

\begin{tabular}{|c|c|c|}
\hline Strain & Relevant characteristics & Reference \\
\hline L. lactis NZ9800 pDF05 & $\begin{array}{l}\text { L. lactis NZ9800 harboring pDF05 (plasmid pCl372 with nisA under its own } \\
\text { promoter). Wild type nisin A producer }\end{array}$ & Field et al., 2008 \\
\hline L. lactis NZ9800 pDF11 & L. lactis NZ9800 harboring pDF11 (pCl372-nisA-M21V) & Field et al., 2008 \\
\hline L. lactis NZ9800 pDF12 & L. lactis NZ9800 harboring pDF12 (pCl372-nisA-14V) & Field et al., 2015b \\
\hline S. aureus SA113 & Representative staphylococcal organism in model virulence studies & Kristian et al., 2003 \\
\hline S. aureus RF122 & $\begin{array}{l}\text { Represents the most common S. aureus clone derived from bovine mastitis } \\
\text { worldwide. }\end{array}$ & Fitzgerald et al., 1997 \\
\hline S. aureus DPC5243 & Bovine mastitis-associated strain & Fitzgerald et al., 1997 \\
\hline S. aureus DPC5247 & Bovine mastitis-associated strain & Fitzgerald et al., 1997 \\
\hline S. aureus ST528 (MRSA) & Methicillin resistant $S$. aureus clinical isolate (BSAC)a & Piper et al., 2009b \\
\hline S. aureus ST534 (MRSA) & Methicillin resistant $S$. aureus clinical isolate $(B S A C)^{a}$ & Piper et al., 2009b \\
\hline S. pseudintermedius DK729 & UCC culture collection. Canine pathogen, biofilm former. & Field et al., 2015b \\
\hline S. pseudintermedius DSM21284 & $\begin{array}{l}\text { Type strain from lung tissue of cat. } \\
\text { Biofilm former }\end{array}$ & Devriese et al., 2005 \\
\hline S. intermedius DSM20373 & $\begin{array}{l}\text { Type strain from pigeon nares. } \\
\text { Biofilm former }\end{array}$ & Hájek, 1976 \\
\hline
\end{tabular}

aritish Society for Antimicrobial Chemotherapy. 
to rotary-evaporation to remove acetonitrile and freeze-dried (LABCONCO). The purified peptides were subjected to MALDIToF Mass Spectrometric analysis to confirm their purity before use.

\section{Growth Curve Experiments}

For growth experiments, overnight cultures were transferred $\left(10^{7} \mathrm{cfu} \mathrm{ml}^{-1}\right.$ in a volume of $1.0 \mathrm{ml}$.) into CA-MH supplemented with the relevant concentration of nisin wildtype, nisin derivatives, and antibiotic/peptide combinations, and subsequently $0.2 \mathrm{ml}$ was transferred to 96 well microtitre plates (Sarstedt). Cell growth was measured spectrophotometrically over 24-h periods by using a SpectraMax M3 spectrophotometer (Molecular Devices, Sunnyvale, CA, USA).

\section{Biofilm Formation and Biofilm Treatment With Purified Nisin A, Nisin Derivative, and Antibiotic Combinations}

Static microtitre plate assays based on a previous study (Kelly et al., 2012), but with modifications to optimize the assay, were used to investigate the biofilm formation and nisin/antibiotic combination treatments. TSB (Merck) broth supplemented with $1 \% \mathrm{D}$-(+)-glucose (Sigma Aldrich) (TSBg) was used in these assays which aids in biofilm formation. Briefly, a 1: 100 dilution was performed by adding $2 \mu \mathrm{l}$ of log phase cells $\left(10^{7} \mathrm{CFU} \mathrm{ml^{-1 }}\right.$ of each culture) to $198 \mu \mathrm{l}$ of TSBg in wells of a sterile 96-well microtitre plate (Sarstedt, Leicester, UK), giving a starting inoculum of $10^{5} \mathrm{CFU} \mathrm{ml} \mathrm{m}^{-1}$; $200 \mu \mathrm{l}$ of TSBg was added to a set of wells as a negative control. All wells were seeded in triplicate. Microtitre plates were then incubated at $37^{\circ} \mathrm{C}$ for $48 \mathrm{~h}$ to allow biofilm formation to occur. After biofilms were established and washed once with phosphate buffered saline (PBS), nisin peptides were added to the microtitre plate wells at $1 \mathrm{X}, 2 \mathrm{X}, 4 \mathrm{X}$, $8 \mathrm{X}$, and $16 \mathrm{X}$ the relevant MIC as previously determined. All wells were seeded in triplicate. Following incubation for $24 \mathrm{~h}$, at $37^{\circ} \mathrm{C}$, the plates were removed and gently washed once with PBS, then $100 \mu \mathrm{L}$ of a solution containing $500 \mathrm{mg}$ XTT/L (2,3-bis[2-methyloxy-4-nitro-5-sulfophenyl]-2Htetrazolium-5-carboxanilide) (Sigma) and $10 \mathrm{mM}$ menadione (Sigma) was added to each well. Microtitre plates were incubated for $2 \mathrm{~h}$ at $37^{\circ} \mathrm{C}$ in the dark. Absorbance was measured at $490 \mathrm{~nm}$ using a microtiter plate reader (Molecular Devices Spectramax M3, Sunnyvale CA, USA). Data obtained in triplicate were calculated and expressed as the mean \pm SD.

\section{Confocal Microscopy}

Biofilms of S. pseudintermedius DSM21284 were pre-formed on $\mu$-Plate 96 well uncoated microtitre plates (Ibidi, Germany) suited to confocal microscopy applications. Following peptide treatment, biofilms were rinsed once with PBS and stained by using a Live/Dead BacLight viability kit (Molecular Probes). $100 \mathrm{ml}$ of the solution containing SYTO 9 and propidium iodide mixed in a ratio of 1:1 was added to the biofilm. The films were incubated at room temperature for $15 \mathrm{~min}$ in the dark. After incubation, residual stain was removed. The images were observed using a Zeiss LSM 5 exciter confocal microscope with a Plan-Apochromat 63x/1.40 Oil DIC M27 lens and images were acquired using the Zen 2008 SP2 software. Sample were excited using laser light at $488 \mathrm{~nm}$ with emission light filtered with a bandpass filter at 505-530 nm for Syto 9 and a longpass filter at $650 \mathrm{~nm}$ for propidium iodide (PI). Images were acquired using two separate confocal channel (one for Syto 9 and one for PI) with pinhole adjusted to 1 (confocal pinhole) at $1556 \times 1556$ pixels.

\section{RESULTS}

\section{MIC-Based Investigations of Antibiotics}

MICs for a range of antibiotics, representing penicillins, cephalosporins, glycopeptides, macrolides, aminoglycosides as well as tetracycline, were carried out to establish suitable concentrations for combinatorial studies with nisin and the derivatives nisin $\mathrm{V}(\mathrm{M} 21 \mathrm{~V})$ and nisin $\mathrm{I} 4 \mathrm{~V}$. The MIC was determined to be the lowest concentration of antibiotic that resulted in the absence of visible growth of the target strain after $16 \mathrm{~h}$ at $37^{\circ} \mathrm{C}$ in CA-MH. S. aureus SA113, DPC5243, DPC5247, and RF122 proved to be susceptible to the majority of the antibiotics utilized in the study (Table 2), with the exception of ceftazidime (CZ). The MRSA isolate ST528 displayed high MICs to erythromycin, chloramphenicol, ampicillin, ceftazidime and cefuroxime (Table 2). In contrast, MRSA ST530 remained sensitive to erythromycin and chloramphenicol.

Staphylococcus pseudintermedius DK729 and S. pseudintermedius DSM21284 both displayed a MIC of $>16 \mu \mathrm{g} / \mathrm{ml}$ for erythromycin, while $S$. pseudintermedius DK729 exhibited MICs of $32,>32$, and $8 \mu \mathrm{g} / \mathrm{ml}$ for ampicillin, ceftazidime and cefuroxime, respectively (Table 2). S. intermedius DSM20373 remained sensitive to erythromycin, tetracycline, penicillin and chloramphenicol but displayed high MIC values of $>32 \mu \mathrm{g} / \mathrm{ml}$ for both ceftazidime and cefuroxime. These results highlight the multi-drug resistant nature of isolates of $S$. intermedius and S. pseudintermedius. Indeed, methicillin resistant $S$. pseudintermedius (MRSP) isolates have been reported that are also typically resistant to aminoglycosides, fluoroquinolones, macrolides, lincosamides, trimethoprim sulfamethoxazol, and, in many cases, to tetracycline and chloramphenicol (Yoo et al., 2010; Yoon et al., 2010).

\section{Growth Curve-Based Comparisons of the Activity of Nisin A, Nisin Derivatives, and Antibiotic Combinations}

Having established the MIC values for a range of antibiotics against the representative staphylococci, growth curves were performed in order to reveal more subtle features of the impact of sub-lethal concentrations of nisin $\mathrm{A}$, nisin $\mathrm{V}$, and nisin $\mathrm{I} 4 \mathrm{~V}$ alone, but also in combination with a selection of antibiotics on bacterial growth. The final concentration of nisin used for each organism was determined on the basis of MIC results obtained previously against these indicator strains (Field et al., 2010, 2015b). One microorganism was chosen from each group to represent drug sensitive strains (SA113), animal 
TABLE 2 | Minimum inhibitory concentration results of a selection of antibiotics against representative staphylococcal targets.

\begin{tabular}{|c|c|c|c|c|c|c|c|c|c|}
\hline $\begin{array}{l}\text { Staphylococcus } \\
\text { Strain }\end{array}$ & $\begin{array}{l}\text { Van } \\
\mu \mathrm{g} / \mathrm{ml} \\
(>2)\end{array}$ & $\begin{array}{l}\text { Ery } \\
\mu \mathrm{g} / \mathrm{ml} \\
\quad(>2)\end{array}$ & $\begin{array}{l}\text { Tet } \\
\mu \mathrm{g} / \mathrm{ml} \\
(>2)\end{array}$ & $\begin{array}{l}\text { PenG } \\
\mu \mathrm{g} / \mathrm{ml}\end{array}$ & $\begin{array}{c}\mathrm{Cm} \\
\mu \mathrm{g} / \mathrm{ml} \\
(>8)\end{array}$ & $\begin{array}{l}\text { Strep } \\
\mu \mathrm{g} / \mathrm{ml}\end{array}$ & $\begin{array}{l}\text { Amp } \\
\mu \mathrm{g} / \mathrm{ml} \\
\quad(>2)\end{array}$ & $\begin{array}{c}\mathrm{CZ} \\
\mu \mathrm{g} / \mathrm{ml} \\
(>4)\end{array}$ & $\begin{array}{c}\text { CF } \\
\mu \mathrm{g} / \mathrm{ml} \\
(>4)\end{array}$ \\
\hline S. aureus SA113 & 0.488 & 0.25 & 0.125 & 0.0195 & 4 & 2.5 & 0.125 & 6.20 & 0.4 \\
\hline S. aureus RF122 & 0.976 & 0.488 & 1.0 & $>10$ & 2 & 5 & 3 & 16 & 2 \\
\hline S. aureus DPC5243 & 0.976 & 0.488 & 1 & 0.156 & 8 & 5 & 1 & 32 & 4 \\
\hline S. aureus DPC5247 & 0.976 & 0.488 & 1 & 0.156 & 8 & 80 & 2 & 32 & 4 \\
\hline \multicolumn{10}{|l|}{ MRSA } \\
\hline S. aureus ST528 & 0.625 & $>16$ & 0.25 & 5 & 16 & 40 & $>64$ & $>32$ & $>32$ \\
\hline S. aureus ST534 & 0.625 & 0.5 & 0.25 & 0.312 & 8 & 40 & 8 & 32 & 8 \\
\hline \multicolumn{10}{|c|}{ S. pseud/intermedius } \\
\hline S. pseudintermedius & 1.95 & $>16$ & 4 & $>10$ & 4 & 80 & 32 & $>32$ & 8 \\
\hline \multicolumn{10}{|l|}{ DK729 } \\
\hline S. pseudintermedius & 7.81 & $>16$ & $>32$ & 0.078 & 8 & $>80$ & 0.125 & 16 & 0.5 \\
\hline \multicolumn{10}{|l|}{ DSM21284 } \\
\hline S. intermedius & 1.95 & 0.5 & 4 & 0.01 & 2 & 2.5 & 0.125 & $>32$ & $>32$ \\
\hline DSM20373 & & & & & & & & & \\
\hline
\end{tabular}

associated pathogens (S. pseudintermedius DSM21284) and drugresistant human clinical organisms (MRSA ST528). It was decided that penicillin and chloramphenicol should be included for combinatorial analysis given previous reports of synergism between these antibiotics and nisin A (Lebel et al., 2013; Tong et al., 2014). Indeed, in our studies, a slight increase in lag time was evident when $S$. aureus SA113 was grown in the presence of sub-lethal concentrations of nisin $(0.937 \mu \mathrm{M} ; 3.0 \mu \mathrm{g} / \mathrm{ml})$ and chloramphenicol $(1.5 \mu \mathrm{g} / \mathrm{ml})$ combined, compared to either compounds used alone (Figure 1A). However, a greatly extended lag time was evident in the case of the nisin derivative $\mathrm{I} 4 \mathrm{~V}+$ chloramphenicol and nisin $\mathrm{V}+$ chloramphenicol combinations. In contrast, when nisin and nisin derivatives were combined with vancomycin $(0.5 \mu \mathrm{g} / \mathrm{ml})$, no enhanced antimicrobial effect was apparent since the combinations produced a shorter lag time than when vancomycin was used alone (Figure 1B). The nisin $(0.937 \mu \mathrm{M} ; 3 \mu \mathrm{g} / \mathrm{ml})$ and penicillin $(0.005 \mu \mathrm{g} / \mathrm{ml})$ and nisin derivative/penicillin combinations had little to no effect on the growth of SA113 at the concentrations used (Figure 1C).
When S. pseudintermedius DSM 21284 was employed, nisin A caused a slight delay in growth relative to the non nisincontaining control at the concentration of peptide used $(0.2 \mu \mathrm{M}$; $0.6 \mu \mathrm{g} / \mathrm{ml}$ ) (Figure 2A). Identical concentrations of nisin I4V resulted in a greatly extended lag time, highlighting its greater potency as previously observed (Field et al., 2015b). Furthermore, when combined with penicillin $(0.8 \mu \mathrm{g} / \mathrm{ml})$, the nisin $\mathrm{I} 4 \mathrm{~V}$ + penicillin combination appeared to completely inhibit the growth of S. pseudintermedius DSM 21284. This impact was not apparent for any other combination of nisin or nisin variant $(\mathrm{M} 21 \mathrm{~V})$ and penicillin or when any antimicrobial compound was used alone (Figure 2A). Indeed, the benefits of employing I4V were evident when combinations of nisin and nisin derivatives with chloramphenicol (Figure 2B), vancomycin (Figure 2C), and erythromycin (Figure 2D) were used in that the longest lag in growth was observed for the nisin $\mathrm{I} 4 \mathrm{~V}$ and antibiotic combination compared to all others tested.

Infections caused by antibiotic-resistant strains of $S$. aureus have reached epidemic proportions globally. Indeed, the overall burden of staphylococcal disease particularly that caused by
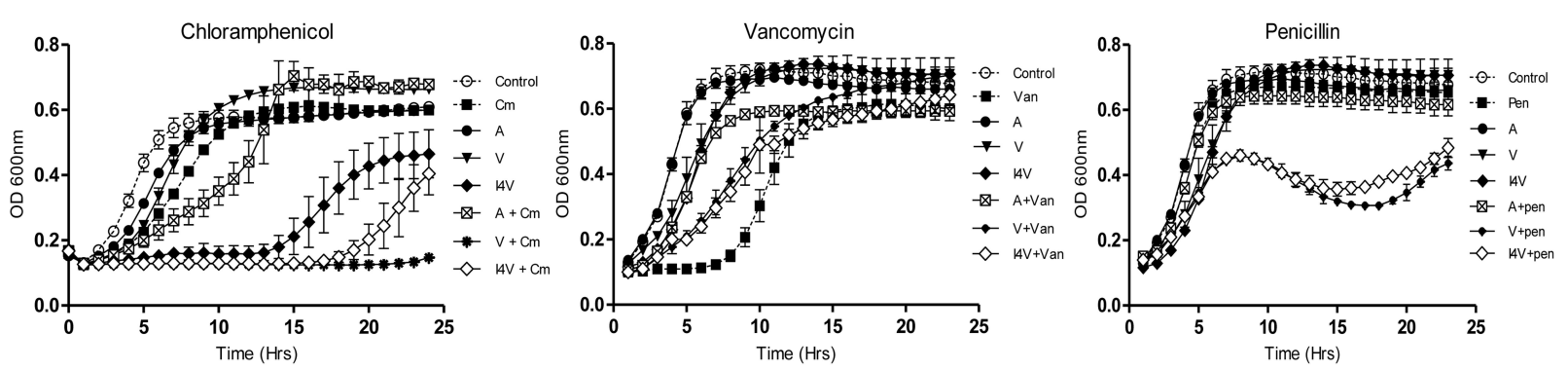

FIGURE 1 | Growth curve analysis of Staphylococcus aureus SA113 in the presence of nisin A (A), nisin V (V), and nisin I4V (I4V) peptides (0.937 $\mu$ M; $3.0 \mu \mathrm{g} / \mathrm{ml}$ ) and in combination with $1.5 \mu \mathrm{g} / \mathrm{ml}$ chloramphenicol (Cm), $5.0 \mu \mathrm{g} / \mathrm{ml}$ vancomycin (Van) and $0.005 \mu \mathrm{g} / \mathrm{ml}$ penicillin (Pen). The means and standard deviations of three independent determinations are presented. 

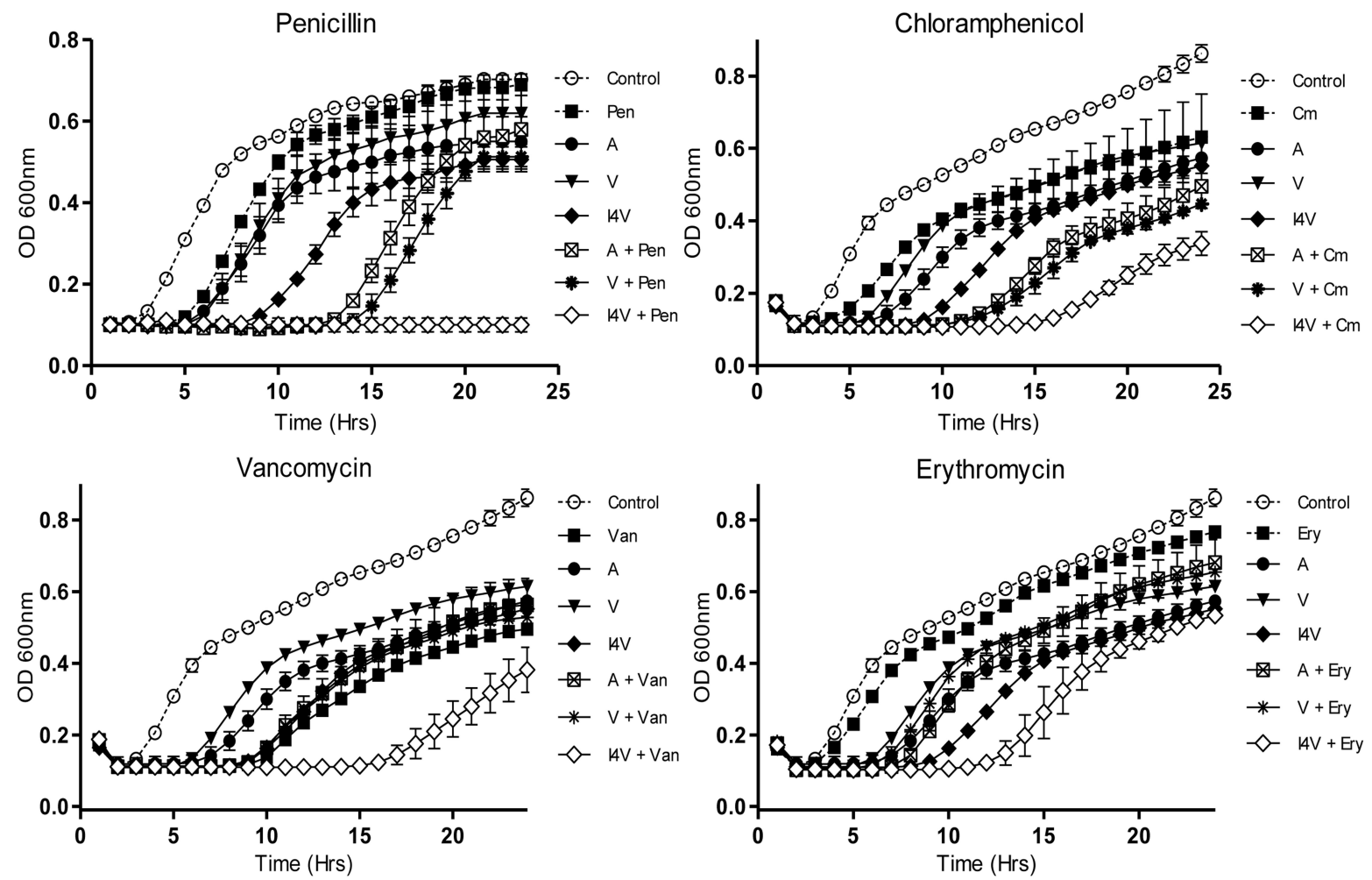

FIGURE 2 | Growth curve analysis of S. pseudintermedius DSM21284 in the presence of nisin A (A), nisin V (V), and nisin I4V (I4V) peptides (0.292 $\mu$ M; $0.932 \mu \mathrm{g} / \mathrm{ml}$ ) and in combination with $0.8 \mu \mathrm{g} / \mathrm{ml}$ penicillin (Pen), $3.0 \mu \mathrm{g} / \mathrm{ml}$ chloramphenicol (Cm), $0.5 \mu \mathrm{g} / \mathrm{ml}$ vancomycin (Van), and $4.0 \mu \mathrm{g} / \mathrm{ml}$ erythromycin (Ery). The means and standard deviations of three independent determinations are presented.

methicillin resistant $S$. aureus strains (MRSA), is increasing in many countries in both healthcare and community settings (Chambers and Deleo, 2009). Consequently, we wished to explore the potential of nisin derivative/antibiotic combinations to inhibit the methicillin resistant S. aureus ST528 (MRSA) strain chosen as the representative clinical pathogen for combinatorial experiments and growth curve analysis. While the derivatives nisin $\mathrm{V}$ and I4V produced a slightly longer delay in growth than the wild type nisin A peptide $(0.2 \mu \mathrm{M})$, combinations of nisin and the variants with chloramphenicol $(2.5 \mu \mathrm{g} / \mathrm{ml})$ and vancomycin $(0.2 \mu \mathrm{g} / \mathrm{ml})$ did not produce any greater inhibitory effect than when any of the compounds were used alone (Figures $3 \mathbf{B}, \mathbf{C}$ ). Similarly, no additional inhibitory effect was observed when penicillin $(2.0 \mu \mathrm{g} / \mathrm{ml})$ was utilized (data not shown) and this trend was also observed when streptomycin $(2.0 \mu \mathrm{g} / \mathrm{ml})$ was applied (Figure 3A).

\section{Investigation of the Anti-Biofilm Activity of Nisin and Antibiotic Combinations}

In addition to specific antibiotic resistance, staphylococci have non-specific mechanisms of resistance, of which biofilm formation is undoubtedly the most important (Jain and Agarwal, 2009). Although a number of methods have been developed for cultivation and quantification of biofilms (Stepanović et al., 2007) including the tube test, radiolabeling, microscopy, and Congo red agar plate test, the microtiter plate method remains among the most frequently used assays for investigation of biofilms (O'Toole, 2011). Here, we employed the rapid colorimetric XTT assay to study pre-formed biofilms of $S$. aureus SA113 and S. pseudintermedius DSM21284 since this method provides evidence relating to the viability of the remaining biofilm cells following combinatorial peptide/antibiotic treatment which cannot be established via crystal violet staining and because it allows the study of intact biofilms.

In view of the enhanced inhibitory effect of nisin, nisin $\mathrm{V}$, and nisin I4V derivatives + chloramphenicol combinations against vegetative cells of $S$. aureus SA113 (Figure 1A), we sought to determine if these combinations could also be effective against pre-formed biofilms. Following preliminary experiments with 1X, 2X, 4X, and 6X MIC of nisin and chloramphenicol alone (data not shown), biofilms of $S$. aureus SA113 formed on a 96-well plate were incubated with nisin and nisin derivative peptides at a concentration of $6 \mathrm{X}$ MIC $(15 \mu \mathrm{M} ; 50.2 \mu \mathrm{g} / \mathrm{ml})$, chloramphenicol at $2 \mathrm{X} \mathrm{MIC}(8 \mu \mathrm{g} / \mathrm{ml})$ and combinations thereof for $24 \mathrm{~h}$. The results revealed that while chloramphenicol alone had no significant effect ( $p=0.2156)$ compared to the untreated control, nisin, and nisin variants as well as the peptide/antibiotic combinations did result in a significant decrease in biofilm viability compared to the untreated control (Figure 4A). Notably, 
the metabolic activity of biofilms treated with nisin $\mathrm{V}+$ chloramphenicol and $\mathrm{I} 4 \mathrm{~V}+$ chloramphenicol combinations was significantly diminished ( $p=0.0002$ and $p=0.0005$, respectively) compared to the nisin A + chloramphenicol treatment. Indeed, this result was in agreement with the observed enhanced effect with similar peptide/antibiotic combinations in growth curve analysis against vegetative cells of $S$. aureus SA113 (Figure 1A).

For nisin treatment alone of pre-formed S. pseudintermedius DSM21284 biofilms, a concentration of $4 \mathrm{X}$ MIC $(1.25 \mu \mathrm{M}$; $4.19 \mu \mathrm{g} / \mathrm{ml}$ ) was chosen since previous studies had established that no significant difference was observed in biofilm mass of S. pseudintermedius DSM21284 treated with 4X MIC of I4V peptide compared to the wild-type nisin A treated biofilms (Field et al., 2015b). Preliminary treatments of established S. pseudintermedius DSM21284 biofilms with $1 / 2 \mathrm{X}(4 \mu \mathrm{g} / \mathrm{ml})$, 1X $(8 \mu \mathrm{g} / \mathrm{ml})$, and 2X MIC $(16 \mu \mathrm{g} / \mathrm{ml})$ of chloramphenicol concentrations revealed that only at $2 \mathrm{X}$ MIC was a minor reduction in the biofilm viability observed as determined by XTT assay (data not shown). Thus, for combinatorial experiments, nisin $\mathrm{A}$ and nisin derivatives were used alone at $4 \mathrm{X}$ MIC, chloramphenicol at $1 \mathrm{X} \mathrm{MIC}$ and the relevant combinations thereof. Following addition of XTT and optical density readings at $492 \mathrm{~nm}\left(\mathrm{OD}_{492}\right)$, no substantial change in biofilm viability was observed following $24 \mathrm{~h}$ treatment with nisin $\mathrm{A}$ and nisin derivatives alone, chloramphenicol alone, or nisin/chloramphenicol combinations (Figure 4) with the exception of nisin $\mathrm{I} 4 \mathrm{~V}+$ chloramphenicol, where biofilm viability was virtually undetectable compared to the XTT (negative) control (Figure 4B). To assess the visual impact of nisin + antibiotic treatments, the experiment was repeated to enable visualization of the treated biofilms using confocal microscopy in conjunction with the BacLight LIVE/DEAD staining kit which facilitates differentiation between active and dead cells (Figure 5). The results revealed that the lower fluorescence signalsobserved for the nisin $\mathrm{I} 4 \mathrm{~V}+$ chloramphenicol treated biofilm compared to that for all other
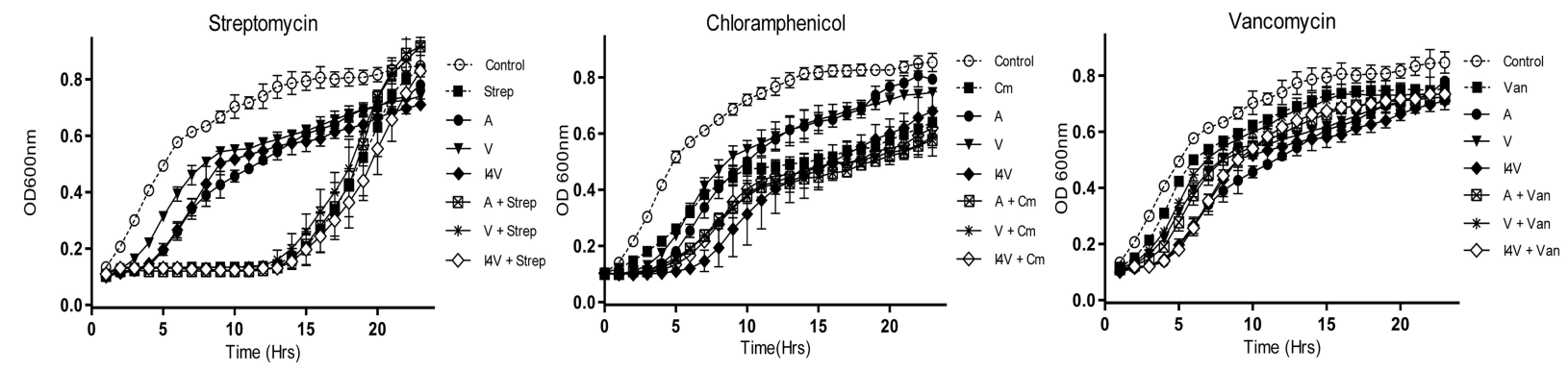

FIGURE 3 | Growth curve analysis of S. aureus ST528 (MRSA) in the presence of nisin A (A), nisin V (V), and nisin I4V (I4V) peptides (0.2 $\mu$ M) and in combination with $10 \mu \mathrm{g} / \mathrm{ml}$ streptomycin (Str), $2.5 \mu \mathrm{g} / \mathrm{ml}$ chloramphenicol $(\mathrm{Cm})$ and $0.2 \mu \mathrm{g} / \mathrm{ml}$ vancomycin (Van). The means and standard deviations of three independent determinations are presented.

A

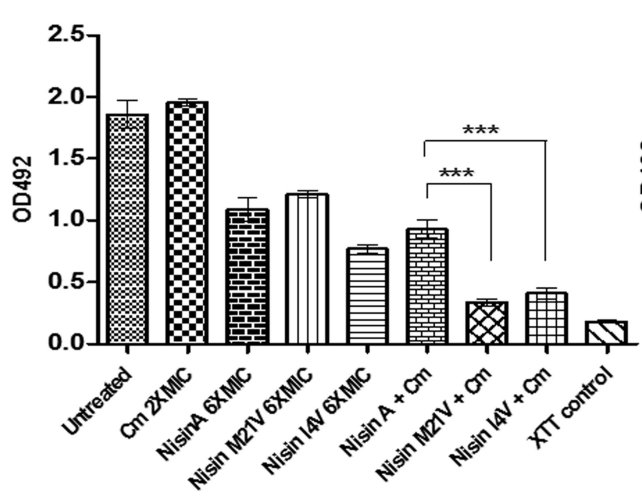

B

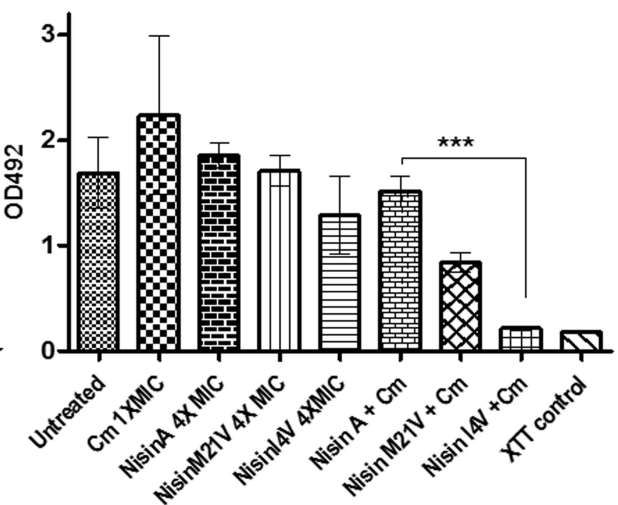

FIGURE 4 | Viability of biofilms of (A) S. aureus SA113 untreated, and treated with 6X MIC (15 $\mu$ M) of nisin A, nisin V (M21V), and nisin I4V and peptides alone and in combination with $2 X$ MIC chloramphenicol for $24 \mathrm{~h}$ and (B) S. pseudintermedius DSM 21284 treated with $4 X$ MIC (1.25 $\mu$ M) of nisin A, nisin V (M21V), and nisin I4V peptides alone and in combination with 1X MIC chloramphenicol for $24 \mathrm{~h}$ as evaluated by XTT (2,3-bis[2-methyloxy-4-nitro-5-sulfophenyl]-2H-tetrazolium-5-carboxanilide) assay measured using a microtiter plate reader. The means and standard deviations of triplicate determinations are presented. Asterisks indicate statistically significant differences (Student's $t$-test) between peptide and antibiotic combinations used at similar concentration $(* * * p<0.001)$. 

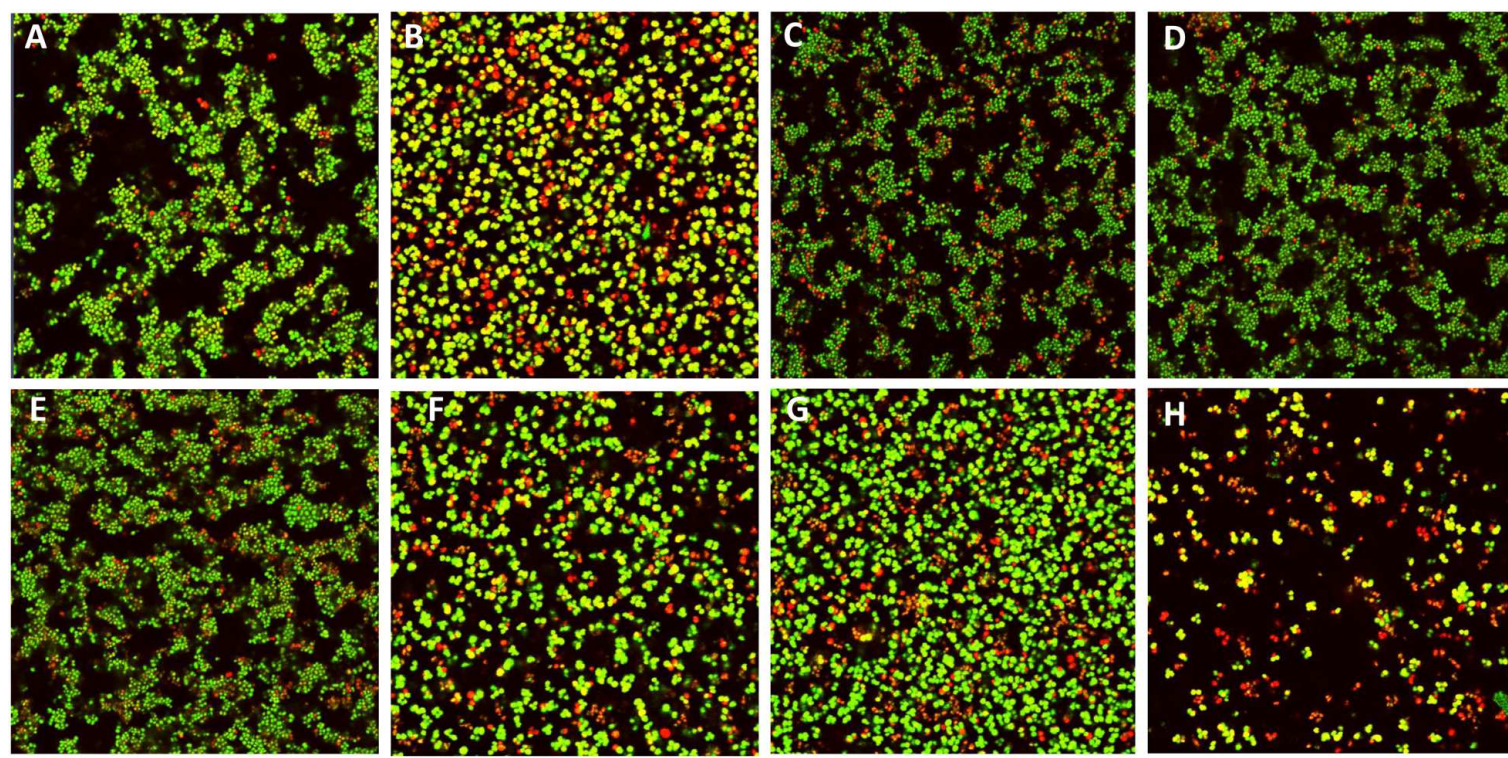

FIGURE 5 | Live/dead staining confocal images of S. pseudintermedius DSM21284 biofilms (A) untreated, (B) chloramphenicol (Cm) $1 \mathrm{X} \mathrm{MIC} \mathrm{(8} \mu \mathrm{g} / \mathrm{ml})$,

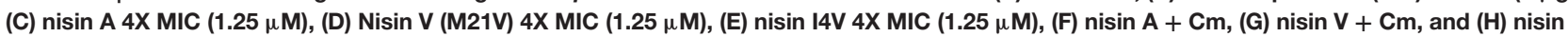
I4V $+\mathrm{Cm}$.

treatments was not due to less metabolic activity attributable to cell death alone, but also as a result of the reduction in biofilm density following treatment (Figure $5 \mathbf{H}$ ).

\section{DISCUSSION}

Staphylococci are commensal bacteria living on the epithelial surfaces of humans and other mammals, and many including S. aureus, S. epidermidis, and S. pseudintermedius, can cause severe disease when they breach the epithelial barrier. Ominously, antibiotic resistance is widespread in staphylococci, significantly complicating treatment. Moreover, many staphylococci form biofilms, complex structures that confer increased resistance to chemotherapies and host defense mechanisms, making infections difficult to eradicate. Recently, the dramatic rise in antibiotic-resistance has stimulated renewed efforts to identify, develop or redesign existing antimicrobial agents active against these multi-resistant bacteria. Due to their many unique properties, the lantibiotics have become the focus of many biomedical and pharmaceutical research groups due to their demonstrable high potency in vitro, multiple modes of action and ability to destroy target cells rapidly (Cotter et al., 2005a; Cavera et al., 2015a). Furthermore, because lantibiotics such as nisin are produced as gene-encoded pre-peptides, they are infinitely more suited than classical antibiotics to bioengineering which could lead to the generation of a new source of potent antimicrobials. Here, we set out to examine for the first time, the ability of nisin and two enhanced bioengineered nisin derivatives (nisin $\mathrm{V}$ and nisin I4V) in conjunction with a selection of conventional antibiotics to control a range of Staphylococcus sp, including human and veterinary pathogens, with the ultimate aim of identifying superior anti-biofilm combinations. Indeed, following MIC determinations and growth curve analysis in the presence of nisin, nisin V, nisin I4V and selected antibiotic combinations, enhanced inhibitory relationships between nisin + penicillin and nisin + chloramphenicol were observed, but were antibiotic and strain dependent. No synergy was observed for nisin + vancomycin combinations against any of the strains tested. Previous studies have confirmed that synergistic interactions between nisin and vancomycin against MSSA and MRSA can vary widely (Dosler and Gerceker, 2011, 2012). Similarly, nisin + penicillin proved highly efficacious in combination against $S$. pseudintermedius DSM21284 but not S. aureus SA113 or MRSA (ST528), while chloramphenicol and nisin combinations proved effective against $S$. pseudintermedius and S. aureus SA113 but not S. aureus ST528 (MRSA). While this is in agreement with previous reports revealing that nisin and chloramphenicol antagonized each other and did not inhibit the growth of 18 of the 19 MRSA strains tested (Brumfitt et al., 2002), studies involving E. faecalis have demonstrated synergism between nisin and chloramphenicol and indeed nisin and penicillin (Tong et al., 2014). Importantly, this synergism also extended to biofilms since confocal laser scanning microscopy revealed that penicillin, ciprofloxacin, and chloramphenicol all displayed stronger anti-biofilm actions in combination with nisin than when these antibiotics were administered alone (Tong et al., 2014). Notably, from the point of view of this study, the derivatives nisin $\mathrm{V}$ and $\mathrm{I} 4 \mathrm{~V}$ both displayed greater potency than nisin A when combined with penicillin and chloramphenicol against $S$. aureus SA113 biofilms. Similarly, nisin $\mathrm{I} 4 \mathrm{~V}+$ chloramphenicol proved to be the most effective combination against preformed biofilms of $S$. pseudintermedius DSM21284, not only in killing biofilm-associated cells but also 
in reducing the density of established biofilm (as observed by a decrease in both green and red fluorescence signals). These findings are significant and represent the first report of bioengineered nisin peptides that are improved in combination with specific antibiotics against planktonic or biofilm-associated cells. The findings also further highlight the merits of employing antibiotic combination strategies to enhance the efficacy of available antibiotics, and ultimately, restore sensitivity and reduce their minimum effective dose. These approaches appear particularly promising for combinations of antimicrobials that target different sites. Surprisingly, many studies have shown that the penetration of antibiotics is not lacking in bacterial biofilms. For example, vancomycin diffuses rapidly in biofilms of S. epidermidis (Darouiche et al., 1994) and MRSA (Okuda et al., 2013), but exhibits diminished antimicrobial efficacy on bacteria in the biofilm environment. Critically, a number of studies have shown that nisin is bactericidal as a result of its ability to access even the deepest part of a biofilm matrix (Davison et al., 2010; Okuda et al., 2013). Notably, the results generated in this study suggest that specific therapies such as bioengineered nisin peptide and antibiotic combinations may be more efficacious against biofilms, and permit the dose of the individual antimicrobials to be reduced and consequently counter the development of drug-resistance in bacteria. Additionally, the opportunity also exists to combine nisin $\mathrm{V}$ and nisin $\mathrm{I} 4 \mathrm{~V}$ with other antimicrobial agents, including naturally derived compounds including essential oils, diterpenoids and thiazolidinone derivatives that affect biofilms via non-microbiocidal mechanisms, but instead target specific molecular pathways that regulate biofilm formation (Buommino et al., 2014). Furthermore, given that resistance to antimicrobials that target lipid II does not develop easily, combinations of lipid II-targeting compounds may also be indispensable given that it is becoming more and more evident that this essential wall precursor plays a key role in organization of the membrane (Scheffers and Tol, 2015).

From a commercial perspective, it is notable that neither nisin A nor any other lantibiotic is currently employed commercially as a clinical antimicrobial. Its potential with respect to clinical applications is strengthened by laboratory based experiments highlighting its activity against human pathogens, including multi-drug resistant strains (Cotter et al., 2005a; Piper et al., 2009a). Nisin or nisin variants could be applied in the form of a topical therapy as a treatment for generalized bacterial skin infections, and/or used as an adjunct to systemic therapy. Alternatively, nisin could also be an effective inhibitor of biofilms which form on in-dwelling devices or hospital equipment. Notably, although $S$. epidermidis and $S$. aureus have been shown to form in vivo biofilms on implanted devices and are the most common pathogens associated with infections of

\section{REFERENCES}

Archer, N. K., Mazaitis, M. J., Costerton, J. W., Leid, J. G., Powers, M. E., and Shirtliff, M. E. (2011). Staphylococcus aureus biofilms: properties, regulation, and roles in human disease. Virulence 2, 445-459. doi: 10.4161/viru.2.5.17724 surgical implants and other prosthetic devices, the ability to form a biofilm is only recently gaining attention in the case of S. pseudintermedius (Singh et al., 2013).

Although a number of drawbacks pertaining to lantibiotic peptides and their suitability for use as therapeutics are apparent, including low bioavailability and high cost of production, these obstacles may be overcome since a broad range of technologies have been developed for the engineering of lantibiotics. Indeed, the past decade has seen several bioengineering studies describe the generation of peptide derivatives including nisin with enhanced functionality in terms of specific activity, spectrum of activity, solubility and/or temperature and $\mathrm{pH}$ stability (Field et al., 2015a). Additionally, genetic systems are in continuous development to increase yields of peptide that may aid commercial viability (Kong and Lu, 2014). The further application of these systems to enhance nisin and other lantibiotics has the potential to lead to the development of novel derivatives for therapeutic use and contribute to a solution to antibiotic resistance across a broad range of bacterial pathogens. In conclusion, we have demonstrated the superior capacity of bioengineered nisin derivatives in combination with classical antibiotics to bring about the destruction of established staphylococcal biofilms of S. aureus and S. pseudintermedius, which may have future applications for the elimination of problematic biofilms and associated infections.

\section{AUTHOR CONTRIBUTIONS}

Conceived and designed the experiments: DF, PC, RR, CH. Performed the experiments: DF and RO. Analyzed the data: DF. Contributed reagents/materials/analysis tools: $\mathrm{CH}$ and RR. Wrote the paper: $\mathrm{DF}, \mathrm{PC}$, and $\mathrm{CH}$.

\section{FUNDING}

DF, CH, PC, RR are supported by the Irish Government under the National Development Plan, through a Science Foundation Ireland (SFI) Technology and Innovation Development Award (TIDA 14/TIDA/2286) to DF, a SFI Investigator awards to $\mathrm{CH}$ and RR (10/IN.1/B3027), SFI-PI funding (11/PI/1137) to PC and the Alimentary Pharmabiotic Centre under Grant Number SFI/12/RC/2273.

\section{ACKNOWLEDGMENT}

We would like to thank Ian O'Neill for assistance with confocal microscopy.

Bierbaum, G., and Sahl, H. G. (2009). Lantibiotics: mode of action, biosynthesis and bioengineering. Curr. Pharm. Biotechnol. 10, 2-18. doi: $10.2174 / 138920109787048616$

Breukink, E., and de Kruijff, B. (1999). The lantibiotic nisin, a special case or not? Biochim. Biophys. Acta 1462, 223-234. doi: 10.1016/S0005-2736(99)00208-4 
Brumfitt, W., Salton, M. R., and Hamilton-Miller, J. M. (2002). Nisin, alone and combined with peptidoglycan-modulating antibiotics: activity against methicillin-resistant Staphylococcus aureus and vancomycin-resistant enterococci. J. Antimicrob. Chemother. 50, 731-734. doi: 10.1093/jac/dkf190

Buommino, E., Scognamiglio, M., Donnarumma, G., Fiorentino, A., and D'Abrosca, B. (2014). Recent advances in natural product-based anti-biofilm approaches to control infections. Mini Rev. Med. Chem. 14, 1169-1182. doi: 10.2174/1389557515666150101095853

Cavera, V. L., Arthur, T. D., Kashtanov, D., and Chikindas, M. L. (2015a). Bacteriocins and their position in the next wave of conventional antibiotics. Int. J. Antimicrob. Agents 46, 494-501. doi: 10.1016/j.ijantimicag.2015.07.011

Cavera, V. L., Volski, A., and Chikindas, M. L. (2015b). The natural antimicrobial subtilosin a synergizes with lauramide arginine ethyl Ester (LAE), epsilonPoly-L-lysine (Polylysine), Clindamycin Phosphate and Metronidazole, Against the Vaginal Pathogen Gardnerella vaginalis. Probiotics Antimicrob Proteins 7, 164-171. doi: 10.1007/s12602-014-9183-1

Chambers, H. F., and Deleo, F. R. (2009). Waves of resistance: Staphylococcus aureus in the antibiotic era. Nat. Rev. Microbiol. 7, 629-641. doi: $10.1038 /$ nrmicro2200

Chatterjee, C., Paul, M., and Xie, L. (2005). Biosynthesis and mode of action of lantibiotics. Chem. Rev. 105, 633-684. doi: 10.1021/cr030105v

Corbin, A., Pitts, B., Parker, A., and Stewart, P. S. (2011). Antimicrobial penetration and efficacy in an in vitro oral biofilm model. Antimicrob. Agents Chemother. 55, 3338-3344. doi: 10.1128/AAC.00206-11

Cotter, P. D., Hill, C., and Ross, R. P. (2005a). Bacterial lantibiotics: strategies to improve therapeutic potential. Curr. Protein Pept. Sci. 6, 61-75. doi: 10.2174/1389203053027584

Cotter, P. D., Hill, C., and Ross, R. P. (2005b). Bacteriocins: developing innate immunity for food. Nat. Rev. Microbiol. 3, 777-788. doi: 10.1038/nrmicro1273

Cotter, P. D., Ross, R. P., and Hill, C. (2013). Bacteriocins - a viable alternative to antibiotics? Nat. Rev. Microbiol. 11, 95-105. doi: 10.1038/nrmicro2937

Cramton, S. E., Gerke, C., Schnell, N. F., Nichols, W. W., and Götz, F. (1999). The Intercellular Adhesion (ica) locus is present in Staphylococcus aureus and Is Required for Biofilm Formation. Infect. Immun. 67, 5427-5433.

Darouiche, R. O., Dhir, A., Miller, A. J., Landon, G. C., Raad, I. I., and Musher, D. M. (1994). Vancomycin penetration into biofilm covering infected prostheses and effect on bacteria. J. Infect. Dis. 170, 720-723. doi: 10.1093/infdis/170.3.720

Davison, W. M., Pitts, B., and Stewart, P. S. (2010). Spatial and temporal patterns of biocide action against Staphylococcus epidermidis biofilms. Antimicrob. Agents Chemother. 54, 2920-2927. doi: 10.1128/AAC.01734-09

Delves-Broughton, J., Blackburn, P., Evans, R. J., and Hugenholtz, J. (1996). Applications of the bacteriocin, nisin. Antonie Van Leeuwenhoek 69, 193-202. doi: 10.1007/BF00399424

Devriese, L. A., Vancanneyt, M., Baele, M., Vaneechoutte, M., De Graef, E., Snauwaert, C., et al. (2005). Staphylococcus pseudintermedius sp. nov., a coagulase-positive species from animals. Int. J. Syst. Evol. Microbiol. 55, 15691573. doi: 10.1099/ijs.0.63413-0

Dosler, S., and Gerceker, A. A. (2011). In vitro activities of nisin alone or in combination with vancomycin and ciprofloxacin against methicillin-resistant and methicillin-susceptible Staphylococcus aureus Strains. Chemotherapy 57, 511-516. doi: 10.1159/000335598

Dosler, S., and Gerceker, A. A. (2012). In vitro activities of antimicrobial cationic peptides; melittin and nisin, alone or in combination with antibiotics against Gram-positive bacteria. J. Chemother. 24, 137-143. doi: 10.1179/1973947812y.0000000007

Dosler, S., and Mataraci, E. (2013). In vitro pharmacokinetics of antimicrobial cationic peptides alone and in combination with antibiotics against methicillin resistant Staphylococcus aureus biofilms. Peptides 49, 53-58. doi: 10.1016/j.peptides.2013.08.008

Field, D., Begley, M., O'Connor, P. M., Daly, K. M., Hugenholtz, F., Cotter, P. D., et al. (2012). Bioengineered nisin a derivatives with enhanced activity against both gram positive and gram negative pathogens. PLOS ONE 7:e46884. doi: 10.1371/journal.pone.0046884

Field, D., Cotter, P. D., Ross, R. P., and Hill, C. (2015a). Bioengineering of the model lantibiotic nisin. Bioengineered 6, 187-192. doi: 10.1080/21655979.2015.1049781

Field, D., Gaudin, N., Lyons, F., O'Connor, P. M., Cotter, P. D., Hill, C., et al. (2015b). A Bioengineered nisin derivative to control biofilms of Staphylococcus pseudintermedius. PLoS ONE 10:e0119684. doi: 10.1371/journal.pone.01 19684

Field, D., O'Connor, P. M., Cotter, P. D., Hill, C., and Ross, R. P. (2008). The generation of nisin variants with enhanced activity against specific gram-positive pathogens. Mol. Microbiol. 69, 218-230. doi: 10.1111/j.13652958.2008.06279.x

Field, D., Quigley, L., O'Connor, P. M., Rea, M. C., Daly, K., Cotter, P. D., et al. (2010). Studies with bioengineered Nisin peptides highlight the broad-spectrum potency of Nisin V. Microb Biotechnol. 3, 473-486. doi: 10.1111/j.17517915.2010.00184.x

Fitzgerald, J. R., Meaney, W. J., Hartigan, P. J., Smyth, C. J., and Kapur, V. (1997). Fine-structure molecular epidemiological analysis of Staphylococcus aureus recovered from cows. Epidemiol. Infect. 119, 261-269. doi: $10.1017 /$ S0950268897007802

Flemming, H.-C., and Wingender, J. (2010). The biofilm matrix. Nat. Rev. Micro 8, 623-633.

Giacometti, A., Cirioni, O., Barchiesi, F., and Scalise, G. (2000). In-vitro activity and killing effect of polycationic peptides on methicillin-resistant Staphylococcus aureus and interactions with clinically used antibiotics. Diagn Microbiol. Infect Dis. 38, 115-118. doi: 10.1016/S0732-8893(00)00175-9

Hájek, V. (1976). Staphylococcus intermedius, a new species isolated from animals. Int. J. Syst. Bacteriol. 26, 401-408. doi: 10.1099/00207713-26-4-401

Jain, A., and Agarwal, A. (2009). Biofilm production, a marker of pathogenic potential of colonizing and commensal staphylococci. J. Microbiol. Methods 76, 88-92. doi: 10.1016/j.mimet.2008.09.017

Kelly, D., McAuliffe, O., Ross, R. P., and Coffey, A. (2012). Prevention of Staphylococcus aureus biofilm formation and reduction in established biofilm density using a combination of phage $\mathrm{K}$ and modified derivatives. Lett. Appl. Microbiol. 54, 286-291. doi: 10.1111/j.1472-765X.2012.03205.x

Kneuper, H., Cao, Z. P., Twomey, K. B., Zoltner, M., Jäger, F., Cargill, J. S., et al. (2014). Heterogeneity in ess transcriptional organization and variable contribution of the Ess/Type VII protein secretion system to virulence across closely related Staphylocccus aureus strains. Mol. Microbiol. 93, 928-943. doi: 10.1111/mmi.12707

Kong, W., and Lu, T. (2014). Cloning and optimization of a nisin biosynthesis pathway for bacteriocin harvest. ACS Synth. Biol. 3, 439-445. doi: $10.1021 / \mathrm{sb} 500225 \mathrm{r}$

Kristian, S. A., Lauth, X., Nizet, V., Goetz, F., Neumeister, B., Peschel, A., et al. (2003). Alanylation of teichoic acids protects Staphylococcus aureus against Toll-like receptor 2-dependent host defense in a mouse tissue cage infection model. J. Infect. Dis. 188, 414-423. doi: 10.1086/376533

Lebel, G., Piche, F., Frenette, M., Gottschalk, M., and Grenier, D. (2013). Antimicrobial activity of nisin against the swine pathogen Streptococcus suis and its synergistic interaction with antibiotics. Peptides 50, 19-23. doi: 10.1016/j.peptides.2013.09.014

Livermore, D. M. (2000). Antibiotic resistance in staphylococci. Int. J. Antimicrob. Agents 16(Suppl. 1), S3-S10. doi: 10.1016/S0924-8579(00)00299-5

Mataraci, E., and Dosler, S. (2012). In vitro activities of antibiotics and antimicrobial cationic peptides alone and in combination against methicillinresistant Staphylococcus aureus biofilms. Antimicrob. Agents Chemother. 56, 6366-6371. doi: 10.1128/AAC.01180-12

Molloy, E. M., Field, D., Pm, O. C., Cotter, P. D., Hill, C., and Ross, R. P. (2013). Saturation mutagenesis of lysine 12 leads to the identification of derivatives of nisin A with enhanced antimicrobial activity. PLOS ONE 8:e58530. doi: 10.1371/journal.pone.0058530

Murayama, N., Nagata, M., Terada, Y., Okuaki, M., Takemura, N., Nakaminami, H., et al. (2013). In vitro antiseptic susceptibilities for Staphylococcus pseudintermedius isolated from canine superficial pyoderma in Japan. Vet. Dermatol. 24, 126-e129. doi: 10.1111/j.1365-3164.2012. 01103.x

Naghmouchi, K., Le Lay, C., Baah, J., and Drider, D. (2012). Antibiotic and antimicrobial peptide combinations: synergistic inhibition of Pseudomonas fluorescens and antibiotic-resistant variants. Res Microbiol 163, 101-108. doi: 10.1016/j.resmic.2011.11.002

Okuda, K., Zendo, T., Sugimoto, S., Iwase, T., Tajima, A., Yamada, S., et al. (2013). Effects of bacteriocins on methicillin-resistant Staphylococcus aureus biofilm. Antimicrob. Agents Chemother. 57, 5572-5579. doi: 10.1128/AAC.00 888-13 
O’Toole, G. A. (2011). Microtiter dish biofilm formation assay. J. Vis. Exp. 30:2437. doi: $10.3791 / 2437$

Otto, M. (2008). Staphylococcal biofilms. Curr. Top. Microbiol. Immunol. 322, 207-228.

Paul, N. C., Moodley, A., Ghibaudo, G., and Guardabassi, L. (2011). Carriage of methicillin-resistant Staphylococcus pseudintermedius in small animal veterinarians: indirect evidence of zoonotic transmission. Zoo. Public Health 58, 533-539. doi: 10.1111/j.1863-2378.2011.01398.x

Piper, C., Cotter, P. D., Ross, R. P., and Hill, C. (2009a). Discovery of medically significant lantibiotics. Curr. Drug Discov. Technol. 6, 1-18. doi: $10.2174 / 157016309787581075$

Piper, C., Draper, L. A., Cotter, P. D., Ross, R. P., and Hill, C. (2009b). A comparison of the activities of lacticin 3147 and nisin against drug-resistant Staphylococcus aureus and Enterococcus species. J. Antimicrob Chemother. 64, 546-551. doi: 10.1093/jac/dkp221

Rishi, P., Preet Singh, A., Garg, N., and Rishi, M. (2014). Evaluation of nisin-betalactam antibiotics against clinical strains of Salmonella enterica serovar Typhi. J. Antibiot. (Tokyo) 67, 807-811. doi: 10.1038/ja.2014.75

Ruscher, C., Lübke-Becker, A., Wleklinski, C.-G., Şoba, A., Wieler, L. H., and Walther, B. (2009). Prevalence of Methicillin-resistant Staphylococcus pseudintermedius isolated from clinical samples of companion animals and equidaes. Vet. Microbiol. 136, 197-201. doi: 10.1016/j.vetmic.2008.10.023

Scheffers, D. J., and Tol, M. B. (2015). LipidII: just another brick in the wall? PLoS Pathog. 11:e1005213. doi: 10.1371/journal.ppat.1005213

Sears, P. M., Smith, B. S., Stewart, W. K., Gonzalez, R. N., Rubino, S. D., Gusik, S. A., et al. (1992). Evaluation of a nisin-based germicidal formulation on teat skin of live cows. J. Dairy Sci. 75, 3185-3190. doi: 10.3168/jds.S0022-0302(92)78083-7

Singh, A., Walker, M., Rousseau, J., and Weese, J. S. (2013). Characterization of the biofilm forming ability of Staphylococcus pseudintermedius from dogs. BMC Vet. Res. 9:93. doi: 10.1186/1746-6148-9-93

Stepanović, S., Vuković, D., Hola, V., Bonaventura, G. D., Djukić, S., ĆIrković, I., et al. (2007). Quantification of biofilm in microtiter plates: overview of testing conditions and practical recommendations for assessment of biofilm production by staphylococci. APMIS 115, 891-899. doi: 10.1111/j.16000463.2007.apm_630.x
Stryjewski, M. E., and Corey, G. R. (2014). Methicillin-resistant Staphylococcus aureus: an evolving pathogen. Clin. Infect. Dis. 58(Suppl. 1), S10-S19. doi: $10.1093 / \mathrm{cid} / \mathrm{cit} 613$

Tong, S. Y., Davis, J. S., Eichenberger, E., Holland, T. L., and Fowler, V. G. Jr. (2015). Staphylococcus aureus infections: epidemiology, pathophysiology, clinical manifestations, and management. Clin. Microbiol. Rev. 28, 603-661. doi: 10.1128/CMR.00134-14

Tong, Z., Zhang, Y., Ling, J., Ma, J., Huang, L., and Zhang, L. (2014). An in vitro study on the effects of nisin on the antibacterial activities of 18 antibiotics against Enterococcus faecalis. PLoS ONE 9:e89209. doi: 10.1371/journal.pone.0089209

Viguier, C., Arora, S., Gilmartin, N., Welbeck, K., and Kennedy, R. (2009). Mastitis detection: current trends and future perspectives. Trends Biotechnol. 27, 486493. doi: 10.1016/j.tibtech.2009.05.004

Wu, J., Hu, S., and Cao, L. (2007). Therapeutic effect of nisin Z on subclinical mastitis in lactating cows. Antimicrob. Agents Chemother. 51, 3131-3135. doi: 10.1128/AAC.00629-07

Yoo, J. H., Yoon, J. W., Lee, S. Y., and Park, H. M. (2010). High prevalence of Fluoroquinolone- and Methicillin-resistant Staphylococcus pseudintermedius isolates from canine pyoderma and otitis externa in veterinary teaching hospital. J. Microbiol. Biotechnol. 20, 798-802.

Yoon, J. W., Lee, K. J., Lee, S. Y., Chae, M. J., Park, J. K., Yoo, J. H., et al. (2010). Antibiotic resistance profiles of Staphylococcus pseudintermedius isolates from canine patients in Korea. J. Microbiol. Biotechnol. 20, 1764-1768.

Conflict of Interest Statement: The authors declare that the research was conducted in the absence of any commercial or financial relationships that could be construed as a potential conflict of interest.

Copyright (c) 2016 Field, O' Connor, Cotter, Ross and Hill. This is an open-access article distributed under the terms of the Creative Commons Attribution License (CC BY). The use, distribution or reproduction in other forums is permitted, provided the original author(s) or licensor are credited and that the original publication in this journal is cited, in accordance with accepted academic practice. No use, distribution or reproduction is permitted which does not comply with these terms. 